\title{
Hydrogel coated monoliths for enzymatic hydrolysis of penicillin $\mathbf{G}$
}

\author{
K. M. de Lathouder • M. W. Smeltink • \\ A. J. J. Straathof · M. A. Paasman • \\ E. J. A. X. van de Sandt · F. Kapteijn · J. A. Moulijn
}

Received: 14 December 2007 / Revised: 19 March 2008 / Accepted: 4 April 2008 / Published online: 22 April 2008

(C) The Author(s) 2008

\begin{abstract}
The objective of this work was to develop a hydrogel-coated monolith for the entrapment of penicillin $\mathrm{G}$ acylase (E. coli, PGA). After screening of different hydrogels, chitosan was chosen as the carrier material for the preparation of monolithic biocatalysts. This protocol leads to active immobilized biocatalysts for the enzymatic hydrolysis of penicillin $\mathrm{G}$ (PenG). The monolithic biocatalyst was tested in a monolith loop reactor (MLR) and compared with conventional reactor systems using free PGA, and a commercially available immobilized PGA. The optimal immobilization protocol was found to be $5 \mathrm{~g}^{-1}$ PGA, $1 \%$ chitosan, $1.1 \%$ glutaraldehyde and $\mathrm{pH}$ 7. Final PGA loading on glass plates was $29 \mathrm{mg} \mathrm{ml}^{-1}$ gel. For 400 cpsi monoliths, the final PGA loading on functionalized monoliths was $36 \mathrm{mg} \mathrm{ml}^{-1}$ gel. The observed volumetric reaction rate in the MLR was $0.79 \mathrm{~mol} \mathrm{~s}^{-1} \mathrm{~m}^{-3}{ }_{\text {monolith. }}$. Apart from an initial drop in activity due to wash out of PGA at higher ionic strength, no decrease in activity was observed after five subsequent activity test runs. The storage stability of the biocatalysts is at least a month without loss of activity. Although the monolithic biocatalyst as used in the MLR is still outperformed by
\end{abstract}

K. M. de Lathouder $(\bowtie) \cdot$ M. W. Smeltink · F. Kapteijn ·

J. A. Moulijn

Faculty of Applied Sciences, DelftChemTech,

Delft University of Technology, Julianalaan 136,

2628 BL Delft, The Netherlands

e-mail: karen.delathouder@shell.com

\section{A. J. J. Straathof}

Department of Biotechnology,

Delft University of Technology,

Julianalaan 67, 2628 BC Delft, The Netherlands

M. A. Paasman - E. J. A. X. van de Sandt

DSM Anti-Infectives B.V., A. Fleminglaan 1,

2613 AX Delft, The Netherlands the current industrial catalyst (immobilized preparation of PGA, $4.5 \mathrm{~mol} \mathrm{~s}^{-1} \mathrm{~m}^{-3}$ catalyst), the rate per gel volume is slightly higher for monolithic catalysts. Good activity and improved mechanical strength make the monolithic bioreactor an interesting alternative that deserves further investigation for this application. Although moderate internal diffusion limitations have been observed inside the gel beads and in the gel layer on the monolith channel, this is not the main reason for the large differences in reactor performance that were observed. The $\mathrm{pH}$ drop over the reactor as a result of the chosen method for $\mathrm{pH}$ control results in a decreased performance of both the MLR and the packed bed reactor compared to the batch system. A different reactor configuration including an optimal $\mathrm{pH}$ profile is required to increase the reactor performance. The monolithic stirrer reactor would be an interesting alternative to improve the performance of the monolith-PGA combination.

Keywords Monolith · Chitosan · Entrapment ·

PenicillinG $\cdot$ Bioreactor

\section{List of symbols}

$C_{\mathrm{b}} \quad$ bulk substrate concentration $\left(\mathrm{mol} \mathrm{m}^{3}\right)$

$d_{b} \quad$ bed diameter $(\mathrm{m})$

$d_{\mathrm{m}} \quad$ monolith diameter $(\mathrm{m})$

$d_{\mathrm{p}} \quad$ particle diameter $(\mathrm{m})$

$\left(E_{0}\right) \quad$ initial enzyme concentration $\left(\mathrm{mol} \mathrm{m}^{-3}\right)$

$L_{\mathrm{b}} \quad$ bed height of catalyst bed with immobilized preparation $(\mathrm{m})$

$L_{\text {chitosan }} \quad$ layer thickness (m)

$L_{\mathrm{m}} \quad$ monolith length (m)

$V_{\mathrm{L}} \quad$ reaction volume $\left(\mathrm{m}^{3}\right)$

$\varepsilon_{\mathrm{b}} \quad$ bed porosity (-)

$\varepsilon_{m} \quad$ monolith porosity (-)

$\rho \quad$ density $\left(\mathrm{kg} \mathrm{m}^{-3}\right)$ 


\section{Introduction}

Biopolymer supports for enzyme immobilization have certain advantages over other polymeric materials such as low cost, ease of enzyme accessibility, hydrophilic character, and presence of hydroxyl and amine groups on the surface for interaction with proteins. Enzyme immobilization on these supports is quick, apparently irreversible, and provides a nontoxic and biocompatible microenvironment conducive to the catalytic activity and stability of the enzyme. Hydrogels of natural polymers such as gelatin, chitosan, xanthan, and agarose can be used conveniently in both wet and dried states. However, these supports suffer from low mechanical strength and ease of microbial degradation. Also the particulate nature of these carriers usually leads to severe diffusion problems inside the carrier beads. The use of a thin layer of hydrogel on a monolith support can strongly reduce these problems.

The term hydrogels refers to a range of polysaccharides and proteins that are widely used nowadays [1,2]. Applications include thickening and gelling of aqueous solutions, use as super absorbents [3], the use in stabilizing foams, emulsions and dispersions [4], inhibiting ice and sugar crystal formation, the controlled release of flavors and drugs [5, 6], and enzyme immobilization [7, 8]. Immobilization can be done during gelation by adding a cross-linker to the gelling agent or by enzyme addition after gel preparation. Simultaneous gelation and immobilization often leads to deactivation [9], therefore immobilization after gel formation was applied. In this work, penicillin $G$ acylase (PGA) was immobilized in different gel matrices; alginate, agarose, gelatin, and chitosan.

It is known [10] that $\mathrm{Ca}^{2+}$ alginate gels are not stable against chelating agents such as phosphate ions, and therefore less suitable for PGA immobilization from phosphate buffer. Also there are some reports that suggest a decreased activity of immobilized enzyme in $\mathrm{Ca}^{2+}$ alginate due to interaction between the protein and $\mathrm{Ca}^{2+}[11]$. Agarose and gelatin gels are very susceptible to dehydration, but shrinkage can be partially reversed by addition of water. Gel formation in a gelatin solution is a thermally reversible process. Gelatin can therefore only be used at ambient temperature, although addition of a suitable cross-linking agent could extend the temperature range to elevated temperatures. For chitosan gels, however, extensive swelling of the gel is frequently observed. The $\mathrm{pH}$ of the solution plays a fundamental role on the swelling degree of the matrix. Chitosan is a basic carbohydrate with amino groups ( $\mathrm{pKa}$ is 6.3) [11], and positively charged at $\mathrm{pH}$ below 6.3 , implying a higher concentration of amino groups as salt $\left(\mathrm{NH}_{3}{ }^{+}\right)$. Due to electrostatic repulsion between carbohydrate chains, swelling is observed. Neutralizing the gels that are formed in an alkaline solution can reduce the swelling of chitosan films. Fixing the polymer chains by cross-linking is also an effective tool to decrease swelling [12].

The immobilization of PGA on chitosan powder, particles and beads was already extensively investigated in 1989 [13]. The immobilization of catalase into chitosan beads prepared by cross-linking with glyoxyl hydrate and reinforcement with glutaraldehyde was reported by Cetinus and Öztop [14]. Cross-linking of chitosan beads with carbodiimide is also an option; this technique was successfully used for the immobilization of lipase [15]. Recently, glucose oxidase was immobilized in porous gels of chitosan$\mathrm{SiO}_{2}$, cross-linked with formaldehyde [16].

Since the discovery of penicillin G in the 1940s, penicillin and its derivatives have become the most important class of antibiotics, because of their low toxicity and their effectiveness against bacterial infection. The commercial success of the semi-synthetic antibiotics has quickly resulted in a worldwide cost-based market [17]. Penicillin amidohydrolase (E.C. 3.5.1.11) is the official name for penicillin acylase or penicillin amidase [17, 18]. PGA catalyzes the hydrolysis of an amide bond between a carboxylic acid and a $\beta$-lactam nucleus while leaving the $\beta$-lactam intact. Penicillin acylase from $E$. coli is the best-studied penicillin acylase with respect to the synthesis of semi-synthetic antibiotics. The enzyme is a heterodimer with a small $\alpha$-subunit of $23 \mathrm{kDa}$ and a large $\beta$-subunit of $63 \mathrm{kDa}$. The two monomer chains consist of 209 and 557 amino acid residues, respectively [19]. The protein has an approximate diameter of $50 \AA$. The isoelectric point for $E$. coli penicillin acylase has been reported as $\mathrm{pH} 6.8$ [18] and $\mathrm{pH} 6.3$ [20].

Monoliths are structured supports that are characterized by long parallel channels, separated by thin walls (Fig. 1). Compared to conventional trickle bed or stirred reactors, monoliths offer a low pressure drop over the reactor, resistance to plugging, a high mechanical strength, low axial dispersion, and high mass transfer rates due to their high void fraction and large geometric surface area. Monoliths

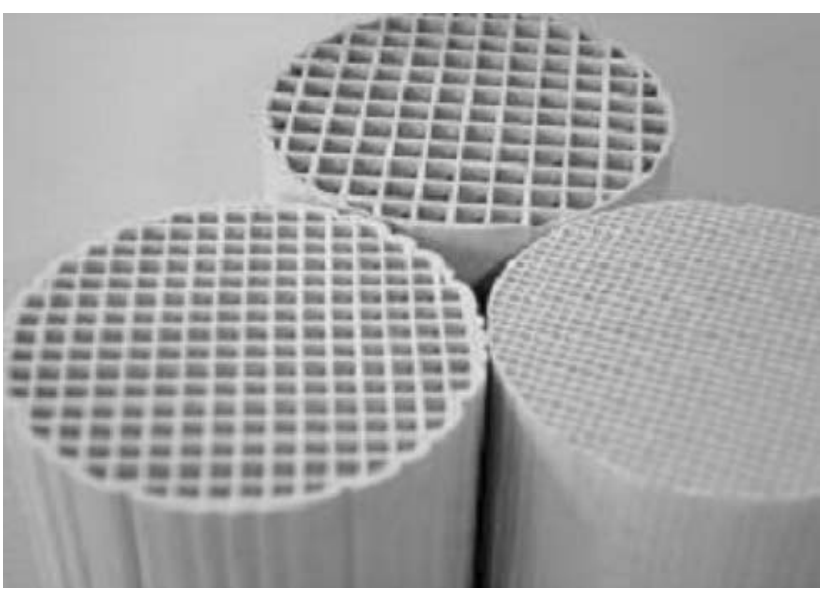

Fig. 1 Ceramic Monoliths of different cell density 
are widely applied in catalytic off-gas treatment, like automotive exhaust gas purification [21], de- $\mathrm{NO}_{\mathrm{x}}$-ing of power plant emissions [22].

The objective of this work is to prepare a hydrogel coating on the interior walls of a monolithic structure for the immobilization of PGA. The biocatalysts will be characterized in terms of activity and stability in the hydrolysis of penicillin $\mathrm{G}$, and will be compared to conventional reactor systems.

\section{Experimental}

\section{Materials}

Colloidal silica solution (Ludox AS-40), agarose type I, and gelatin A (from porcine skin, bloom strength of 300) were purchased from Sigma. Sodium alginate was obtained from Ashland Chemicals. $\gamma$-(Aminopropyl)triethoxysilane (APTES) and low viscous chitosan with viscosity $<200 \mathrm{mPa}$ s were purchased from Fluka. Acetic acid and glutaraldehyde were purchased from Merck. PGA preparations from E. coli, (in solution and immobilized) were kindly supplied by DSM Anti-Infectives, Delft, The Netherlands.

\section{Catalyst preparation}

\section{Gel preparation on glass plates for screening}

Gels were prepared on a glass plate and either used as such or cut into smaller pieces $(2-5 \times 5 \times 5 \mathrm{~mm})$. For immobilization experiments a concentration of $1.0 \%(\mathrm{w} / \mathrm{v})$ was used. Only for gelatin, $3 \%$ was needed to get a rigid gel.

Agarose gels were formed by heating a $1 \%(\mathrm{w} / \mathrm{v})$ solution to $353 \mathrm{~K}$ and subsequent cooling to ambient temperature. The solution was gently stirred for $3 \mathrm{~h}$ prior to cooling.

To prepare the alginate gel, a glass microfiber filter (Whatman GF/A, $90 \mathrm{~mm} \emptyset$ ) placed on a petri dish was soaked in $0.25 \mathrm{~mol} \mathrm{l}^{-1} \mathrm{CaCl}_{2}$ for $60 \mathrm{~min}$ to saturate the filter with calcium. The calcium chloride solution was poured out and replaced with a sodium alginate solution.
Gelatin powder was dissolved in water $(3 \% \mathrm{w} / \mathrm{v})$ and heated to $333 \mathrm{~K}$. Subsequently the solution was cooled to ambient temperature to form the gel. For enzyme binding, a cross-linked gel was prepared by adding $0.05 \%(\mathrm{v} / \mathrm{v})$ glutaraldehyde to the gelatin solution. The gel was washed with demiwater to remove free glutaraldehyde.

Chitosan powder $0.5-2 \%(\mathrm{w} / \mathrm{v})$ was added to $1 \%(\mathrm{v} / \mathrm{v})$ acetic acid and gently stirred $(100 \mathrm{rpm})$ for $3 \mathrm{~h}$ at room temperature. Undissolved matter was removed by filtration over a $100-\mu \mathrm{m}$ filter. A gel was formed by adding $0.5-2 \%$ glutaraldehyde.

\section{Monolith coating with chitosan}

Before coating with a gel, the monoliths were wash-coated with $\mathrm{SiO}_{2}$ and treated with APTES (samples Lx-APTES).

Monoliths ( $400 \mathrm{cpsi}, L_{\mathrm{m}}=4 \mathrm{~cm}, d_{\mathrm{m}}=2 \mathrm{~cm}$ ) were coated with chitosan gel by dip-coating. The monoliths were placed in a $1.0 \% \mathrm{w} / \mathrm{v}$ chitosan solution containing $1.1 \% \mathrm{w} / \mathrm{v}$ glutaraldehyde for $60 \mathrm{~s}$. After clearing the channels, the samples were air-dried (horizontally rotating) for $90 \mathrm{~min}$ (samples Lx-APTES-Chit).

\section{Enzyme immobilization}

Gels $(5 \times 5 \times 5 \mathrm{~mm}$ blocks $)$ were suspended in $30 \mathrm{ml}$ $5 \mathrm{~g} \mathrm{l}^{-1}$ enzyme solution. Immobilization was done at ambient temperature during $24 \mathrm{~h}$ while gently stirring. The protein concentration followed by measuring the absorbance at $280 \mathrm{~nm}$ on a Unicam UV300 UV/vis spectrophotometer. After washing, $20 \mathrm{ml}$ of phosphate buffer $(25 \mathrm{mM} \mathrm{pH} \mathrm{7.0)}$ was added to the gel. Desorption of non-bonded protein took place at ambient temperature during $24 \mathrm{~h}$, while gently stirring. Immobilization on chitosan-coated monoliths was performed in fixed bed set-up (see also Fig. 2c), consisting of a chromatography column with a diameter of $26 \mathrm{~mm}$. Enzyme solution was pumped bottom-up through the column. Immobilization was performed by recycling a total volume of $30 \mathrm{ml}$ through the monolith $\left(2 \mathrm{ml} \mathrm{min}^{-1}\right)$ at room temperature for $24 \mathrm{~h}$. Samples were washed with demiwater to remove unbound enzyme. Biocatalysts were stored until further use.
Fig. 2 Different reactor configurations used in the enzymatic hydrolysis of Pen G at $304 \mathrm{~K}$. STR for batch testing of free and immobilized beads, fixed bed set-up (packed bed reactor for immobilized beads, MLR for monoliths) for batch testing of beads and monoliths
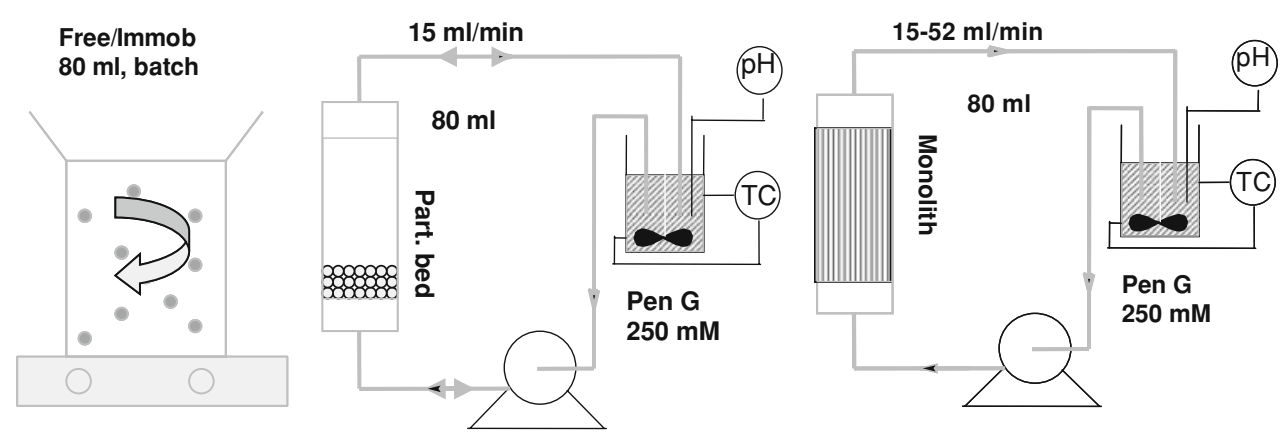


\section{Penicillin G hydrolysis}

To compare the different biocatalysts, three set-ups were used; a stirred batch reactor, a packed bed reactor, and a monolith loop reactor (MLR). The set-ups are schematically depicted in Fig. 2. During storage at $277 \mathrm{~K}$ a slow decomposition of penicillin $\mathrm{G}$ in solution occurs. The inactivation rate constant $k_{\text {inact }}$ was calculated at 0.009 day $^{-1}$, i.e., 9\%o penicillin decomposition per day by HPLC. HPSEC (high performance size exclusion chromatography) was used to detect traces of protein in samples taken from the reaction mixture.

Batch conversions with free enzyme and immobilized preparation (PGA beads) were carried out in $80 \mathrm{ml}$ penicillin solution (initial Pen G-ammonia salt concentration $250 \mathrm{mM}$ ) in a STR, to which the equivalent of $50 \mathrm{mg}$ enzyme $\left[\left(E_{0}\right)=7.8 \times 10^{-3} \mathrm{mmol}^{-1}\right]$ was added. The conversion was measured at $\mathrm{pH} 8.5$ and $T=304 \mathrm{~K}$ by titration with $1.0 \mathrm{M} \mathrm{NaOH}$ of released phenylacetic acid (PAA).

The fixed bed set-up (Fig. 2) was used for penicillin G hydrolysis with monolithic biocatalysts and immobilized preparation in packed bed. Total enzyme loading on the monolithic structure $\left(400 \mathrm{cpsi}, L_{\mathrm{m}}=4 \mathrm{~cm}, d_{\mathrm{m}}=1.9 \mathrm{~cm}\right.$, $\left.\varepsilon_{\mathrm{m}}=0.74\right)$ was $120 \mathrm{mg}$ PGA. To get an enzyme loading of $120 \mathrm{mg}$ with commercial immobilized penG acylase $\left(d_{\mathrm{p}}=0.4 \mathrm{~mm}\right.$ and $\left.\rho_{\text {gel }}=1,050 \mathrm{~kg} \mathrm{~m}^{-3}\right)$, a bed height of $1 \mathrm{~cm}$ was used $\left(d_{\mathrm{b}}=2.6 \mathrm{~cm}, \varepsilon_{\mathrm{b}}=0.448\right)$. The flowrate could be varied between 15 and $53 \mathrm{ml} \mathrm{min}{ }^{-1}$, the total reaction volume was $120 \mathrm{ml}$ (initial Pen G concentration $250 \mathrm{mM}$ ). $\mathrm{NaOH}$ was added to control the $\mathrm{pH}$ in the liquid accumulation vessel.

\section{Characterization}

\section{Gel morphology and distribution}

Scanning electron microscopy (SEM) was applied to investigate the distribution of the chitosan gel over both the length of the monolith and over the cross-section of the channels. Samples were analyzed on a Philips XL-20 scanning electron microscope operated at $12 \mathrm{kV}$.

\section{Results}

Hydrogel selection

An overview of the PGA loading for each gel is displayed in Fig. 3. After loading, the gels were extensively washed with a saline solution to desorb non-covalently bound enzyme from the matrix.

With $1.0 \%$ agarose, strong stiff gels are easily formed within $1 \mathrm{~h}$. These gels were very susceptible to dehydration,

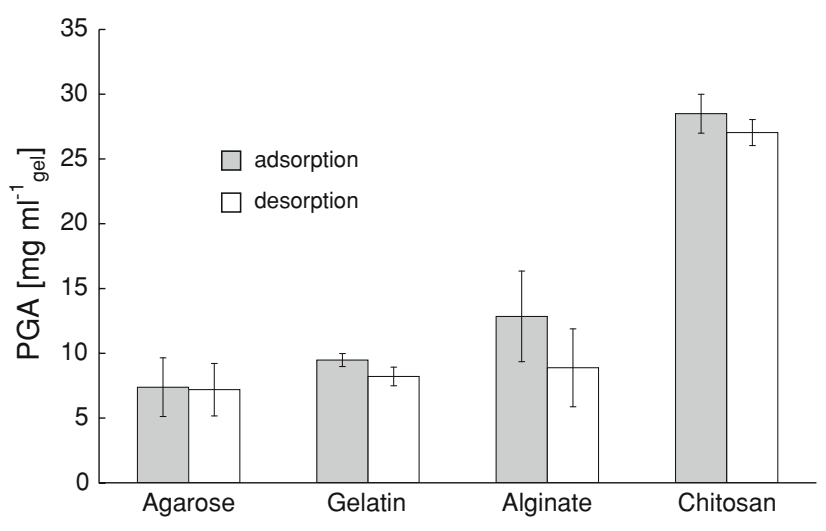

Fig. 3 PGA loading on each type of hydrogel, cut into $5 \times 5 \times 5 \mathrm{~mm}$ blocks. Lines represent the $95 \%$ confidence interval

but shrinkage can be partially reversed by addition of water. A PGA loading of $7.5 \mathrm{mg} \mathrm{ml}^{-1}$ was reached.

Gelatin gels were easy to prepare, although higher concentrations were needed (3\%) than for the other precursors. An enzyme loading of $8.0 \mathrm{mg} \mathrm{ml}^{-1}$ gel could be achieved with a gelatin concentration of $3 \%$.

A colorless, transparent alginate-gel was formed within $45 \mathrm{~min}$, which remained intact in $\mathrm{NaCl}$ solution. This meant that no exchange of $\mathrm{Ca}^{2+}$ and $\mathrm{Na}^{+}$occurred, gel formation was irreversible. No cross-linking agent was used here, thus all enzymes were physically entrapped in the gel matrix. This resulted in a substantial wash out during the desorption step (see Fig. 3). An enzyme loading of $12.5 \mathrm{mg} \mathrm{ml}^{-1}$ alginate gel was reached.

Flexible, yellow and transparent chitosan gels can be formed in $1 \mathrm{~h}$. This gel has the highest immobilization capacity $\left(27.2 \mathrm{mg} \mathrm{ml}^{-1}\right.$ gel). Gel formation can easily be controlled and the gelation occurs gradually. The highest enzyme loading $\left(27 \mathrm{mg} \mathrm{ml}^{-1}\right.$ gel) was achieved on a chitosan hydrogel; therefore, chitosan was selected as the carrier for PGA.

Optimization of PGA immobilization using glass plates

The optimal parameters for PGA immobilization on chitosan gel were determined using $5 \mathrm{~mm}$ gel layers on a glass plate. Chitosan filtrates $0.5 \% \mathrm{w} / \mathrm{v}, 1.0 \% \mathrm{w} / \mathrm{v}$ and $2.0 \% \mathrm{w} / \mathrm{v}$ were used with different degrees of glutaraldehyde crosslinking. Chitosan filtrate of $2.0 \% \mathrm{w} / \mathrm{v}$ chitosan was a very viscous solution, this concentration is considered too high for use within a monolith.

From the results (Fig. 4a) it can be seen that a positive relation exists between the chitosan concentration and the amount of immobilized PGA. The optimal chitosan concentration was determined to be $1 \%$.

Penicillin G acylase loading initially increases with glutaraldehyde concentration, but seems to go through a maximum at around $1 \%$. The optimum glutaraldehyde concentration for this chitosan gel is $1.1 \% \mathrm{v} / \mathrm{v}$ glutaraldehyde 

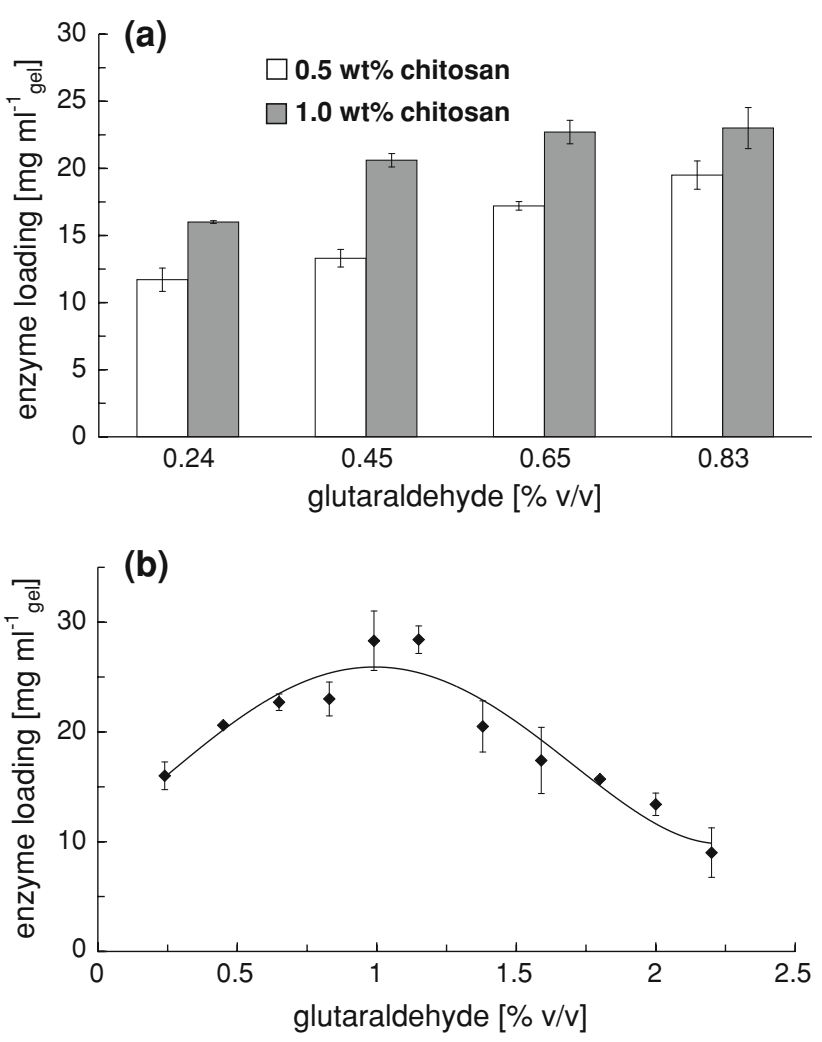

Fig. 4 Optimization of the chitosan protocol. a Chitosan concentration. Glutaraldehyde indicates the glutaraldehyde concentration in the chitosan/glutaraldehyde mixture before gelation. b Glutaraldehyde concentration. Immobilization was performed with an initial concentration of $5 \mathrm{~g}^{-1}$

(Fig. 4b). This value represents the amount of glutaraldehyde in chitosan/glutaraldehyde mixture before gelation.

The optimum $\mathrm{pH}$ for the immobilization of PGA into a chitosan hydrogel is near pH 7 (Fig. 5). The optimal conditions to prepare a PGA loaded chitosan gel were thus set at $5 \mathrm{~g} \mathrm{l}^{-1}$ PGA, pH 7 on a $1.0 \%$ chitosan gel with $1.1 \%$ glutaraldehyde. The final loading under these conditions is around $30 \mathrm{mg} \mathrm{ml}^{-1}$ gel.

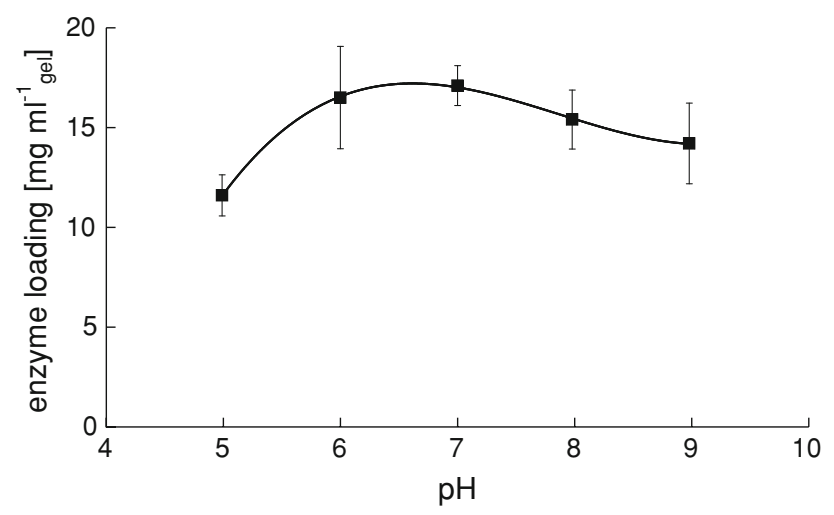

Fig. 5 Effect of $\mathrm{pH}$ on PGA loading at $5 \mathrm{~g} \mathrm{l}^{-1}$ PGA
Chitosan coated monoliths

Assuming a homogeneous gel layer throughout the channel, the average layer thickness is calculated to be around $90 \mu \mathrm{m}$. Layer thickness and enzyme loading are summarized in Table 1. For comparison, the results for bare monoliths (no $\mathrm{SiO}_{2}$ /APTES) are also included.

The immobilization of PGA was followed during $24 \mathrm{~h}$ to establish the time necessary to reach "steady-state" loading. The use of APTES for covalent attachment of the chitosan layer to the monolith surface, has a positive effect on layer thickness and total enzyme loading.

In order to create even more anchors in the chitosan gel for binding PGA, monolith structures (Lx_APTES) were treated with a glutaraldehyde solution subsequent to the gel formation and aging step. This did not improve total PGA loading (see Table 1), but only a slight decrease in the final loading capacity was observed. During immobilization, aggregate formation was observed in the PGA bulk solution. This indicated the release of free glutaraldehyde from the chitosan gel. The aggregates of cross-linked enzymes were unable to diffuse into the gel pores. Aggregate formation within the gel led to blocking of pores, thus preventing additional enzyme binding.

\section{Scanning electron microscopy}

Scanning electron microscopy was performed to investigate the distribution of the chitosan layer in the monolith. Due to the vacuum the gels are completely dehydrated, it is therefore not possible to quantify the layer thickness from the SEM micrographs. Chitosan forms a gel layer over the silica coating both in the center and in the corners of the monolith channels. The macro pores in the cordierite remain (partially) open (Fig. 6a, b).

A gel layer is also found on silica dispersed in the cordierite macro pores, but the pores are not completely filled.

\section{Stability}

The operational stability of PGA on a chitosan coated monolith system was investigated by repeated use of the

Table 1 Monolith coating with chitosan layer (C_Chit), with optional pre-conditioning of the support

\begin{tabular}{llll}
\hline Carrier & Enzyme & $\begin{array}{l}\text { Chitosan } \\
\text { loading/ } / L_{\text {chitosan }} \\
(\% \mathrm{w} / \mathrm{w} / \mu \mathrm{m})\end{array}$ & $\begin{array}{l}\text { Enzyme } \\
\text { loading } \\
\left(\mathrm{mg} \mathrm{ml}^{-1}{ }_{\text {gel }}\right)\end{array}$ \\
\hline Chit & PGA & $24 / 77$ & 32 \\
Lx-APTES-Chit & PGA & $28 / 89$ & 36 \\
$\begin{array}{l}\text { Lx-APTES- } \\
\text { Chit-GA }\end{array}$ & PGA & $28 / 89$ & 30 \\
\hline
\end{tabular}



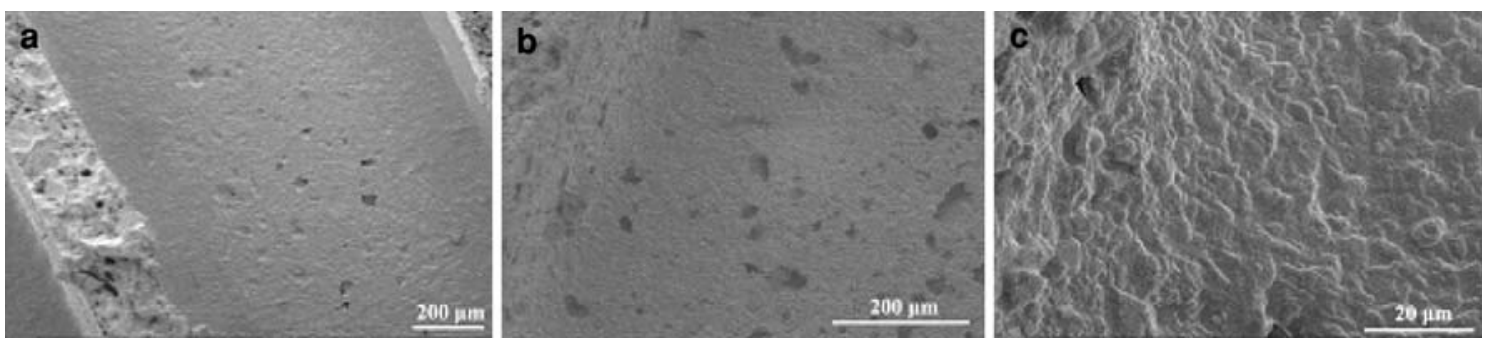

Fig. 6 SEM micrographs of chitosan layers on washcoated and functionalized cordierite. a, b Gel distribution through a functionalized monolith channel, most of the macro pores are filled c) corner of a channel, showing accumulation of gel

same monolith structure under equal reaction conditions (Fig. 7). Activity drops initially, probably due to loss of unbound enzyme. Activity remains constant from the second cycle onwards during four successive conversions and no free protein was detected.

The sample was stored at $277 \mathrm{~K}$ for 35 days between the third and fourth conversion cycle without notable loss of activity. This shows that the storage stability of PGA on a chitosan-coated monolithic structure is at least a month without loss of enzyme activity.

\section{Hydrolysis of penicillin G}

Catalyst performance tests were used to compare the free enzyme, immobilized preparation, and the monolithic biocatalysts under process conditions.

\section{Catalyst performance}

In a set of experiments in a batch reactor $\left(V_{\mathrm{L}}=80 \mathrm{ml}\right.$, $C_{\mathrm{b}}=0.250 \mathrm{~mol} \mathrm{~m}^{-3}$ ) the initial reaction rate of free and immobilized enzyme was determined. In Fig. 8 the initial rates of free and immobilized (monolith/commercial beads) PGA are compared. The chitosan beads show a lower initial rate as compared to the free enzyme. The performance of

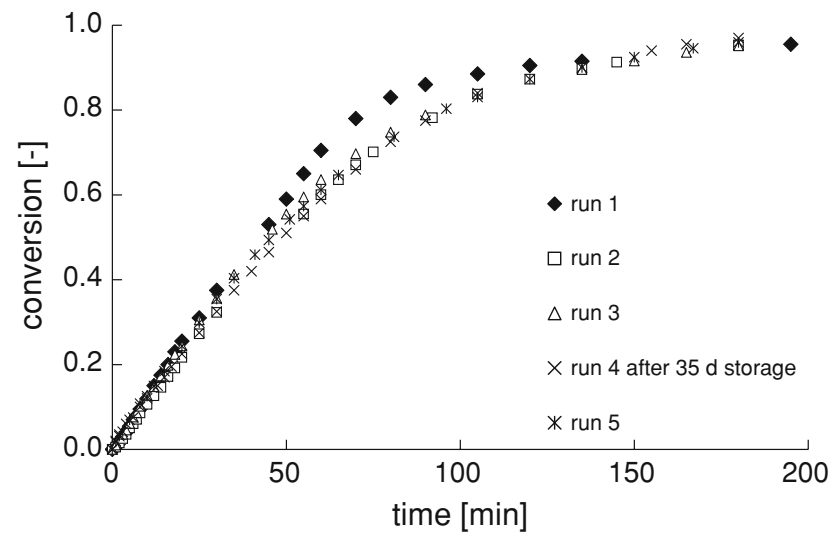

Fig. 7 Conversion of PenG with a monolith-PGA combination during repeated use, at $304 \mathrm{~K}$ and $\mathrm{pH} 8.50$ the monolithic biocatalyst is similar to that of the catalyst beads in STR.

\section{Comparison of the different reactor configurations}

The performance of a monolithic structure in the MLR is compared with the performance of a packed bed of immobilized preparation in the column at different flow rates. Hydrolysis of a $250 \mathrm{~mol} \mathrm{~m}^{-3}$ PenG solution was done with a total enzyme loading in the bed equivalent to the enzyme loading on the monolith $\left(120 \mathrm{mg}, L_{\mathrm{b}} \approx 1 \mathrm{~cm}\right)$ and with monolithic structures loaded with PGA (configurations as presented in Fig. 2). The rate of conversion, represented by the liberation of product (PAA) is presented in Fig. 9. The highest conversion rates were observed for free PGA and immobilized preparation in a STR. It was found that for commercial immobilized PGA, used in a packed bed, the reaction rate is higher in downflow operation than in upflow operation (Fig. 9). The performance of a monolith in the MLR (upflow) is lower than for a catalyst bed in downflow, but higher than for the catalyst bed in upflow operation.

For 400 cpsi monoliths, the volumetric activity is around $0.79 \mathrm{~mol} \mathrm{~s}^{-1} \mathrm{~m}^{-3}$ monolith. Although the MLR does not perform better than the current industrial catalyst $\left(4.5 \mathrm{~mol} \mathrm{~s}^{-1} \mathrm{~m}^{-3}\right.$ catalyst $)$, the intrinsic rates in STR are comparable (Fig. 8).

\section{Discussion \\ Hydrogel selection}

For application on monoliths, the gel should be stable and easily applicable inside the channels. Selection of a suitable hydrogel for the immobilization of PGA should ideally be based on the recovered enzyme activity. This activity, however, depends on enzyme loading, enzyme distribution and substrate/product diffusion. Therefore, only the final enzyme loading (Fig. 3) is used as a selection criterion here.

Alginate is less suitable for entrapment of enzymes because they tend to leach out. An enzyme loading of 


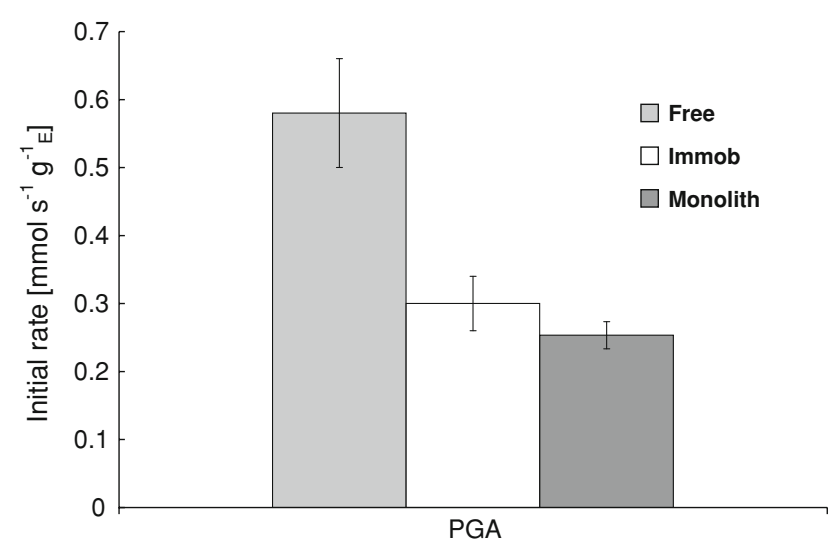

Fig. 8 Initial activity of free enzyme, chitosan beads and a chitosanmonolith in the hydrolysis of Pen $\mathrm{G}$ at $304 \mathrm{~K}$ and $\mathrm{pH}$ 8.50, normalized with respect to enzyme loading

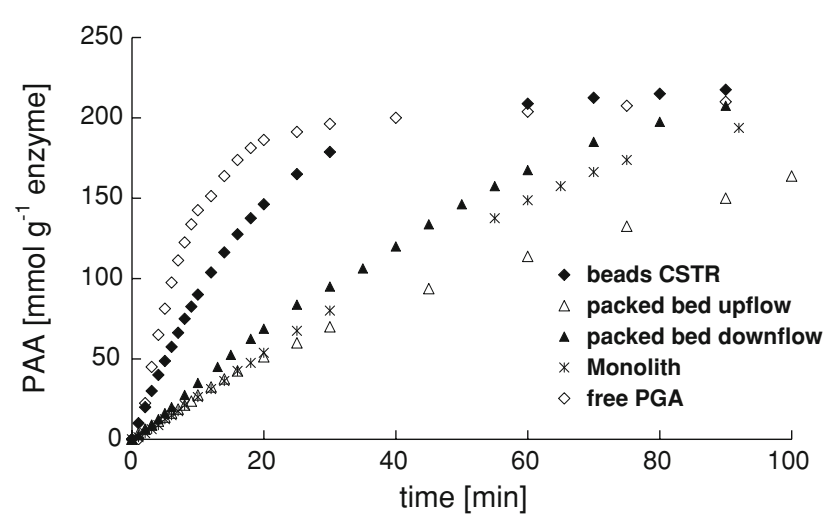

Fig. 9 Product $(P A A)$ concentration over time, representing activity of free $P G A$, immobilized preparation, and monolith reactor. Configurations are presented. PGA loading in the reactor in all tests is $120 \mathrm{mg}$ enzyme, at $304 \mathrm{~K}$ and $\mathrm{pH} 8.50$

$12.5 \mathrm{mg} \mathrm{ml}^{-1}$ alginate gel was reached. It is expected that level will drop even further after more extensive washing. A PGA loading of $7.5 \mathrm{mg} \mathrm{ml}^{-1}$ was reached on agarose gel and a loading of $8.0 \mathrm{mg} \mathrm{ml}^{-1}$ gel could be achieved on the gelatin sample ( $3 \%$ gelatin). No significant shrinkage of these gels was observed. However, the enzyme loading is expected to be too low for use on monoliths. The chitosan gel has the highest immobilization capacity $\left(27.2 \mathrm{mg} \mathrm{ml}^{-1}\right.$ gel). Gel formation can easily be controlled and the gelation occurs gradually. This would make chitosan a very suitable gel to be applied on monolithic structures.

All biopolymers provide physically stable hydrogels. The effect of enzyme loading as a function of layer thickness was observed for all hydrogels. This is in agreement with earlier studies [5, 23]. The application of alginate within the monolith channels seems possible, but a twostep coating is needed. Gelatin can only be used at ambient temperatures, and has a significantly lower loading capacity than chitosan. Both chitosan and gelatin are cross-linked via amine groups with glutaraldehyde. The enzyme is then bound to free glutaraldehyde groups via lysine amino groups. But the loading on gelatin gel is much lower than on chitosan (see Fig. 3). Since gelatin contains less free amino groups (about 27 lysine residues per 1,000 amino acids) than chitosan (1 amino group per repeating unit, 75$80 \mathrm{wt} \%$ of which are deacetylated), theoretical maximum enzyme loading on chitosan is expected to be significantly higher than for gelatin.

Penicillin $G$ acylase loading on agarose could not be increased significantly by modifying the gel, final loading was only $25 \%$ of the final loading on chitosan. The highest enzyme loading ( $27 \mathrm{mg} \mathrm{ml}^{-1} \mathrm{gel}$ ) was achieved on a chitosan hydrogel; therefore, chitosan was selected as the carrier for PGA.

\section{Optimization of PGA immobilization}

The optimal parameters for PGA immobilization on chitosan gel were determined by using 5-mm gel layers on a glass plate (Figs. 4, 5). For all glutaraldehyde concentrations, more enzyme can be bound to the more concentrated gel, because an increased chitosan concentration increases the amount of binding sites (amino groups) present in the gel. But on the other hand, a higher chitosan concentration increases the degree of cross-linking. This negatively affects enzyme loading. An advantage of a more dense gel structure at higher chitosan concentration would be reduced swelling and shrinking effects [12]. The optimal chitosan concentration was determined to be $1 \%$, leaving reasonable flow properties for possible application inside a monolith channel.

The optimum glutaraldehyde concentration for this chitosan gel was found to be $1.1 \% \mathrm{v} / \mathrm{v}$ glutaraldehyde (Fig. 4b). Initially, enzyme loading increases with glutaraldehyde concentration. Above a certain maximum, enzyme loading starts to drop. Two opposing mechanisms seem to determine the position of the maximum; (1) at low concentrations both aldehyde groups in each glutaraldehyde molecule are involved in network formation. As the glutaraldehyde concentration increases an increasing number of free aldehyde groups will be present for binding with a lysine residue in PGA. (2) But at higher glutaraldehyde concentrations the enzyme loading starts to decline due to restrictions by the degree of cross-linking.

The optimum $\mathrm{pH}$ (7) for PGA immobilization (Fig. 5) corresponds to the optimum found for the immobilization of penicillin acylase on nylon particles via glutaraldehyde activation [24], although minimal differences in enzyme loading were observed at $\mathrm{pH} 6-8$. This is confirmed by Braun et al. [13], who reported no significant increase in enzyme loading at $\mathrm{pH}$ 6-8. An explanation for the decrease in immobilization at a $\mathrm{pH}$ outside this range could be 
related to the ionic strength of the immobilization solution, or a negative correlation between enzyme activity and phosphate concentration [24]. Although the effect of salt concentration was not incorporated in this study, it is advised to use only a minimal amount of phosphate to control the immobilization solution at the desired $\mathrm{pH}$. Since the PGA formulation consisted of a low concentration phosphate buffer at $\mathrm{pH} 7.0$, this $\mathrm{pH}$ was set a optimum $\mathrm{pH}$ for this study.

\section{Chitosan-coated monoliths}

The chitosan layer thickness as calculated is an average over the entire monolith structure (Table 1). In practice, however, the gel film in a square channel will not be uniform. As a result of the surface tension during gelation, it will accumulate in the corners resulting in "rounded" channels (Fig. 6c).

Penicillin $G$ acylase immobilization was followed for $24 \mathrm{~h}$. For practical reasons, an immobilization time of $2 \mathrm{~h}$, in which $80 \%$ of equilibrium is reached, is recommended. This approach matches reasonably well with the current industrial immobilization process for PGA-gel particles with a similar diffusional distance $d_{\mathrm{p}} / 6$ as is observed for the gel coatings that are used in this study. Strictly speaking, local layer thickness in the monolith channel is not constant; in the corners, the diffusion distances will be somewhat larger than $d_{\mathrm{p}} / 6$, at the channel wall probably a bit smaller.

PGA loading can be affected by pretreatment of the monolithic support (Table 1). The optimal preparation method of monolith-chitosan supports consists of applying a washcoat and a chemical linker (APTES). Post-immobilization treatment with glutaraldehyde is not recommended.

When investigating the operational stability of the PGAmonoliths, observed activity initially dropped. This was caused by the loss of the unbound enzyme. This was confirmed with HP-SEC analysis for free protein (loss $5.4 \mathrm{mg}$, $7.7 \%$ ). Initial washing does not remove enzyme bound by ionic interactions, but the increased ionic strength in the PenG reaction mixture does remove this loosely bound enzyme. Therefore the introduction of a washing step with a suitable salt solution was suggested. Activity remained constant from the second cycle onwards during four successive conversions and no free protein was detected. This is in agreement with the immobilization of lipase onto chitosan beads [25]. Lipase retained an activity of $92 \%$ after six cycles.

\section{Activity in hydrolysis of penicillin $\mathrm{G}$}

Catalyst performance tests were used to compare the free enzyme, immobilized preparation, and the monolithic bio- catalysts under process conditions (Figs. 8, 9). The chitosan beads seemed to suffer from internal mass transport problems (lower conversion) when compared to the free enzyme, as already described by Schroën et al. [26]. It was found that for this type of matrix the intrinsic reaction rate does not significantly decrease as a result of immobilization [26]. This was validated by grinding commercial PGA particles and comparing the initial rate. The initial rate for the smaller particles was the same as for the free enzyme. An additional problem is the production of acid (PAA). This results in $\mathrm{pH}$ gradients inside the gel matrix due to the coupling of reaction and diffusion of substrates and products within the carrier. This explains the higher apparent reaction rate for the PGA beads in a fluidized bed (STR, see Fig. 8) compared to the same amount of biocatalyst in a packed bed (Fig. 9).

For operation in a packed bed reactor it was found that with commercial immobilized PGA (packed bed), the reaction rate is higher in downflow operation than in upflow operation. From these results, it is clear that the flow direction and reactor configuration have a significant impact on the observed reaction rate. Since no pressure drop exists over the bed, rates of convective mass transfer at the scale of a particle can be assumed equal in both upflow and downflow operation. It is believed that the flow distribution in the radial direction in upflow operation is uneven compared to the downflow regime, leading to a lower observed reaction rate for the downflow-case.

The performance of a monolith in the MLR (upflow) is lower than for a catalyst bed in downflow, but higher than for the catalyst bed in upflow operation. Measurement of $\mathrm{pH}$ in the effluent supports that the conversion rate is equal for monolithic structure and a bed packed with gel beads, because the $\mathrm{pH}$ gradient over the column is the same for both monolith and packed bed. This indicates that an equal amount of substrate has been converted. A fair comparison between the monolith MLR-system and a packed bed of gel beads is difficult due to the existence of external mass transfer limitations. The performance of the MLR seems to be affected by the large initial drop in $\mathrm{pH}$ over the monolith (pH directly drops to around 5, severely limiting further hydrolysis of PenG) and diffusion limitations inside the chitosan gel (also locally the slow diffusion of PAA through the gel causes very low $\mathrm{pH}$ ). These results underline the importance of realizing short diffusion lengths by control of the thickness of a gel layer coated on a monolithic structure. When used in a STR set-up, this effect is diminished by the constant $\mathrm{pH}$ in the reactor, whereas in our tubular reactor (packed bed or monolith) in the axial direction a $\mathrm{pH}$ gradient was present. Alternative configurations should be considered to improve the efficiency of the MLR (intermediate $\mathrm{NaOH}$ addition, different reactor configuration). Although the MLR does not perform better than the current 
industrial catalyst $\left(4.5 \mathrm{~mol} \mathrm{~s}^{-1} \mathrm{~m}^{-3}\right.$ catalyst $)$, the intrinsic rates measured in a stirred system are comparable. When operated in a batch STR configuration, the monolithic biocatalyst shows a significantly higher activity due to the constant $\mathrm{pH}$ in the reactor. This makes the chitosan-based monolithic biocatalyst an interesting alternative for gel beads, worth studying in more detail. An interesting alternative for the MLR in terms of $\mathrm{pH}$ control could be the monolithic stirrer reactor (MSR), in which monoliths are used as stirrer blades. This reactor has been successfully applied for different applications [27, 28], including enzymatic reactions [29].

\section{Conclusions}

Chitosan gel was found to be the best gel for immobilization of PGA. Cross-linked chitosan gel is stable and suitable for use within monolith channels. The immobilization parameters have been optimized, using thin $(200 \mu \mathrm{m})$ chitosan layers coated on a glass surface. The optimal conditions for the immobilization process are:

- $10 \mathrm{~g}^{-1}$ enzyme

- $1.0 \% \mathrm{w} / \mathrm{v}$ chitosan

- $1.1 \% \mathrm{v} / \mathrm{v}$ glutaraldehyde (GA)

- $\mathrm{pH} 7.0$.

Coating of 400 cpsi monoliths with a chitosan layer yields a smooth layer with an average layer thickness of $77 \mu \mathrm{m}$. With an extra washcoating and silanization step, the layer thickness can be increased to $95 \mu \mathrm{m}$. SEM revealed that the gel is evenly distributed along the length of the monolith structures, but most of the chitosan has been accumulated in the corners of the channels.

The optimal preparation method of monolith-chitosan supports consists of applying a washcoat and a chemical linker (APTES). An immobilization time of $2 \mathrm{~h}$ is sufficient to reach $80 \%$ of the maximal enzyme loading. Post-immobilization with glutaraldehyde is not recommended. The loading capacity for PGA on chitosan-coated monoliths is $36 \mathrm{mg} \mathrm{ml}^{-1}$ gel, which is in the same order of magnitude as the enzyme loading achieved on chitosan coated glass plates. For 400 cpsi monoliths, the volumetric activity in the hydrolysis of PenG was $0.79 \mathrm{~mol} \mathrm{~s}^{-1} \mathrm{~m}^{-3}$ monolith. The operational stability was tested in five consecutive reaction cycles. The catalyst lost $7 \%$ of its activity after the first cycle, but no enzyme loss or deactivation was detected over the four subsequent reaction cycles. The monolith system is stable after storage for 35 days. The performance of the current industrial catalyst is superior to the performance of a PGA monolith in a conventional fixed bed set-up (MLR). The reactor set-up has a large impact on the observed reaction rate. In a stirred system, the volumetric activity of the monolith-PGA system increases significantly and approaches the values found for the PGA beads. For the industrial catalyst beads, the same effects are observed; the apparent reaction rate is 2.5 times higher if the bed is fluidized in the reaction vessel than for the same amount of biocatalyst in a packed bed. For these beads however, internal diffusion limitations imposed by immobilization in a gel network, decrease the efficiency of the immobilized enzyme. The observed reaction rate of the PGA beads is $50 \%$ lower than an equal amount of free enzyme. This underlines the importance of realizing short diffusion lengths by control of the layer thickness of a gel coating on a monolithic structure.

The $\mathrm{pH}$-dependence of the reaction is the main problem for the under-performance of the monolith reactor. To address this problem, other reactor configurations need to be explored.

Open Access This article is distributed under the terms of the Creative Commons Attribution Noncommercial License which permits any noncommercial use, distribution, and reproduction in any medium, provided the original author(s) and source are credited.

\section{References}

1. Prichard JG (1970) Poly (vinyl alcohol) basic properties and uses. Gordon and Breach, London

2. Finch CA (1973) Poly (vinyl alcohol) properties and applications. Wiley, London

3. Zhao Y, Su H, Fang L, Tan T (2005) Superabsorbent hydrogels from poly (aspartic acid) with salt-, temperature- and $\mathrm{pH}$-responsiveness properties. Polymer 46(14):5368-5376. doi:10.1016/ j.polymer.2005.04.015

4. Capek I (2002) Sterically and electrosterically stabilized emulsion polymerization. Kinetics and preparation. Adv Colloid Interface Sci 99(2):77-162. doi:10.1016/S0001-8686(02)00005-2

5. Tang C, Yin C, Pei Y, Zhang M, Wu L (2005) New superporous hydrogels composites based on aqueous Carbopol ${ }^{\circledR}$ solution (SPHCcs): synthesis, characterization and in vitro bioadhesive force studies. Eur Polymer J 41(3):557-562. doi:10.1016/j.eurpolymj.2004.10.017

6. Date AA, Patravale VB (2004) Current strategies for engineering drug nanoparticles. Curr Opin Colloid Interface Sci 9:222-235. doi:10.1016/j.cocis.2004.06.009

7. Martinek K, Klibanov AM, Goldmacher VS, Berezin IV (1977) The principles of enzyme stabilization 2 Increase in the thermostability of enzymes as a result of multipoint noncovalent interaction with a polymeric support. Biochim Biophys Acta 485:1-12

8. Bodalo A, Gomez E, Gomez JL, Bastida J, Maximo MF, Diaz F (1991) A comparison of different methods of $\beta$-galactosidase immobilization. Process Biochem 26:349-353

9. Munjal N, Sawhney SK (2002) Stability and properties of mushroom tyrosinase entrapped in alginate, polyacrylamide and gelatin gels. Enzyme Microb Technol 30:613-619. doi:10.1016/S01410229(02)00019-4

10. Mateo C, Abian O, Fernandez-Lafuente R, Guisan JM (2000) Increase in conformational stability of enzymes immobilized on epoxy-activated supports by favoring additional multipoint covalent attachment. Enzyme Microb Technol 26:509-515 
11. Taqieddin E, Amiji M (2004) Enzyme immobilization in novel alginate-chitosan core shell microcapsules. Biomaterials 25:19371945

12. Calleri E, Temporini C, Massolini G, Caccialanza G (2004) Penicillin $\mathrm{G}$ acylase-based stationary phases: analytical applications. J Pharm Biomed Anal 35:243-258. doi:10.1016/S07317085(03)00587-9

13. Braun J, le Chanu P, le Goffic F (1989) The immobilization of penicillin G acylase on chitosan. Biotechnol Bioeng 33:242-246. doi:10.1002/bit.260330217

14. Cetinus SA, Öztop HN (2003) Immobilization of catalase into chemically crosslinked chitosan beads. Enzyme Microb Technol 32:889-894

15. Chiou SH, Wu WT (2004) Immobilization of Candida rugosa lipase on chitosan with activation of the hydroxyl groups. Biomaterials 25:197-204. doi:10.1016/S0142-9612(03)00482-4

16. Yang YM, Wang JW, Tan RX (2004) Immobilization of glucose oxidase on chitosan- $\mathrm{SiO}_{2}$ gel. Enzyme Microb Technol 34:126131. doi:10.1016/j.enzmictec.2003.09.007

17. Bruggink A (ed) (2001) Synthesis of $\beta$-lactam antibiotics, 1 st edn. Dordrecht, The Netherlands, pp 13-54

18. Parmar A, Kumar H, Marwaha SS, Kennedy JF (2000) Advances in enzymatic transformation of penicillins to 6-aminopenicillanic acid (6-APA). Biotechnol Adv 18:289-301. doi:10.1016/S07349750(00)00039-2

19. Duggleby HJ, Tolley JP, Hill CP, Dodson EJ, Dodson G, Moody PCE (1995) Penicillin acylase has a single amino-acid catalytic centre. Nature 373:264-268

20. Patel CB, Gaikar VG (2004) Adsorption and immobilization of penicillin acylase on chitosan beads. Sep Sci Technol 39:2655-2675

21. Twigg MV, Wilkins AJJ (2006) Autocatalysts: past, present and future. In: Cybulski A, Moulijn JA (eds) Structured catalyst and reactors. Marcel Dekker, New York, pp 109-146
22. Nova I, Beretta A, Groppi G, Lietti L, Tronconi E, Forzatti P (2006) Monolithic catalysts for NOx removal from stationary sources. In: Cybulski A, Moulijn JA (eds) Structured catalyst and reactors. Marcel Dekker New York, pp 171-214

23. van Roon JL, Joerink M, Rijkers MPWM, Tramper J, Schroën CGPH, Beeftink HH (2003) Enzyme distribution derived from macroscopic particle behavior of an industrial immobilized penicillin-G acylase. Biotechnol Prog 19:1510-1518

24. Mohy Eldin MS, Schroën CGPH, Janssen AEM, Mita DG, Tramper J (2000) Immobilization of penicillin G acylase onto chemically grafted nylon particles. J Mol Catal B Enzym 10:445-451

25. Roy I, Gupta MN (2004) Hydrolysis of starch by a mixture of glucoamylase and pullulanase entrapped individually in calcium alginate beads. Enzyme Microb Technol 34:26-32. doi:10.1016/ j.enzmictec.2003.07.001

26. Schroën CGPH, Fretz CB, de Bruin VH, Berendsen W, Moody HM, Roos EC, van Roon JL, Kroon PJ, Strubel M, Janssen AEM, Tramper J (2002) Modeling of the enzymatic kinetically controlled synthesis of cephalexin: influence of diffusion limitation. Biotechnol Bioeng 80:331-340

27. Hoek I, Nijhuis TA, Stankiewicz AI, Moulijn JA (2004) Performance of the monolithic stirrer reactor: applicability in multiphase processes. Chem Eng Sci 59(22-23):4975-4981

28. Bakker JJW, Groendijk WJ, de Lathouder KM, Kapteijn F, Moulijn JA, Kreutzer MT, Wallin SA (2007) Enhancement of catalyst performance using pressure pulses on macroporous structured catalysts. Ind Eng Chem Res 46:8574-8583

29. de Lathouder KM, Bakker JJW, Kreutzer MT, Wallin SA, Kapteijn F, Moulijn JA (2006) Structured reactors for enzyme immobilization advantages of tuning the wall morphology. Chem Eng Res Des 84(A5):390-398 